\title{
Perancangan dan I mplementasi Duplexer Mikrostrip untuk Frekuensi LTE pada band ke-7
}

\author{
ENCENG SULAEMAN ${ }^{1}$, ARSYAD RAMADHAN DARLI ${ }^{2}$, R. HARI ANTI ASRI DEWI ${ }^{2}$
}

1. Jurusan Teknik Telekomunikasi Politeknik Negeri Bandung

2. Jurusan Teknik Elektro Institut Teknologi Nasional

Email : enceng_s@yahoo.com

\begin{abstract}
ABSTRAK
Kebutuhan akan komunikasi bergerak semakin mengalami peningkatan dalam dunia teknologi yang ada saat ini, maka hadirlah teknologi terbaru yaitu Long Term Evolution (LTE). Dengan teknik duplex jenis Frequency Division Duplex (FDD), dirancanglah duplexer yang mampu melakukan proses pengiriman dan penerimaan dalam satu waktu dengan frekuensi yang berbeda antara uplink dan downlink. Pada penelitian ini dirancang dan diimplementasikan sebuah duplekser dengan menggunakan metoda Hybrid Coupler dan Bandstop Filter berbasis Split Ring Resonator untuk band frekuensi ke-7 pada teknologi LTE di sisi Base Transceiver Station (BTS). Duplekser dibuat dengan menggabungkan dua buah hybrid Coupler dan dua buah Bandstop Filter. Hasil pengukuran duplexer saat port Tx mengirimkan sinyal ke antena dengan nilai redaman pada frekuensi tengah downlink sebesar $3.168 \mathrm{~dB}$. Lalu pada saat antena menerima sinyal untuk diteruskan ke $R x$ terdapat redaman di frekuensi tengah uplink sebesar $6 d B$. Sedangkan untuk isolasi dari port Tx-port Rx dihasilkan sebesar $15 \mathrm{~dB}$.
\end{abstract}

Kata kunci: Duplexer, Bandstop Filter, Split Ring Resonator, Hybrid Coupler, dan Long Term Evolution.

\begin{abstract}
The necessary of mobile communication has increased in technology, now it released the new of technology is Long Term Evolution (LTE). Type of duplex is Frequency Division Duplex (FDD), designed a duplexer which it is capable for transmitting and receiving process at the same time with the different of frequency between uplink and downlink. Research of designed and implemented a duplexer using Hybrid Coupler and Bandstop filters based on Split Ring Resonators for the frequency band 7th on LTE technology at Base Transceiver Station (BTS). Duplexer is made by combining two coupler and two bandstop filter. The results of duplexer measurements, when Tx port transmit the signal to antenna port with attenuation at the downlink frequency center at $3.168 \mathrm{~dB}$. Attenuation from antenna port to $R x$ port about $6 \mathrm{~dB}$. Isolation between $T x$ port and $R x$ port about $15 d B$.
\end{abstract}

Keywords: Duplexer, Bandstop Filter, Split Ring Resonator, Hybrid Coupler, and Long Term Evolution. 


\section{PENDAHULUAN}

Kebutuhan akan komunikasi bergerak semakin mengalami peningkatan dalam dunia teknologi yang ada pada saat ini. Dengan semakin berkembangnya dunia telekomunikasi maka hadirlah teknologi terbaru yang disebut Long Term Evolution (LTE). LTE menawarkan berbagai kelebihan dibandingkan sistem sebelumnya, antara lain kecepatan akses data yang tinggi, peningkatan jumlah kapasitas kanal, dan dapat melayani komunikasi bergerak dengan performasi yang baik serta dapat menunjang kerja sama antar teknologi.

Sistem komunikasi dalam hal teknik pengiriman dibedakan menjadi 3 jenis yaitu, teknik dengan menggunakan Simplex, Half Duplex, dan Full Duplex. Full Duplex adalah sistem komunikasi dimana proses pengiriman dan penerimaan dapat dilakukan secara simultan. Untuk sistem komunikasi full duplex dibutuhkan sebuah duplexer. Ada dua jenis sistem full duplex: Time Division Duplex (TDD) dan Frequency Division Duplex (FDD). Pada TDD digunakan frekuensi uplink dan downlink yang sama, hanya waktu pengiriman dan penerimaan yang berbeda. Sebaliknya pada FDD waktu pengiriman dan penerimaan bersamaan tapi dengan frekuensi yang berbeda antara uplink dan downlink. (Siburian, 2011)

Sebelumnya duplexer mikrostrip pada frekuensi uplink $2500-2570 \mathrm{MHz}$ dan frekuensi downlink 2620-2690 MHz dengan menggunakan metode Coupler juga Bandstop filter yang disatukan sehingga membentuk sebuah duplexer dan pada saat proses simulasi menggunakan CST Microwave Studio, telah dilakukan oleh Indah Wijayanti. (Wijayanti, 2010) Namun dengan menggunakan software simulator tersebut agak sulit untuk mensimulasikannya.

Lalu Jia-Sheng Hong dan M.J Lancaster, telah merancang duplexer dengan menggunakan metode Tandem Coupler serta Bandstop filter berbasis Open-Loop Resonators dengan mendapatkan hasil spesifikasi sesuai perancangannya. Duplexer yang dibuat terdiri dari dua buah Tandem Coupler dan dua buah Bandstop filter yang dipisahkan dengan skrup dan disambungkan dengan proses penyolderan. (Hong, 2001)

Tandem Coupler sulit untuk direalisasikan dengan mikrostrip karena terdapat airbridge yang dipasang menyilang antara port 1 dan port 2. Hybrid Coupler lebih mudah disimulasikan dan direalisasikan dengan mikrostrip. Bandstop filter diimplementasikan dengan metoda Split Ring Resonator agar ukuran filter dapat diperkecil. Dengan demikian ukuran keseluruhan alat menjadi lebih kecil.

Dalam perancangan dan implementasi duplexer, ditentukan perumusan masalah yaitu, bagaimana membuat strip Coupler dengan menggunakan metode Hybrid Coupler dan strip Bandstop filter berbasis Split Ring Resonators yang disimulasikan pada EM Simulator AWR Design Environment serta bagaimana menggabungkan Coupler dan Bandstop filter menjadi sebuah duplexer. Proses penggabungan tersebut merupakan salah satu cara untuk membuat duplexer, serta disisi lain dapat menekan biaya menjadi lebih murah pada saat proses realisasinya.

Tujuan dilakukannya penelitian ini adalah membuat sebuah duplexer dengan menggunakan mikrostrip, dengan cara menggabungkan dua buah Coupler yang menggunakan metode Hybrid Coupler dan dua buah Bandstop filter (BSF) berbasis Split Ring Resonator dengan mensimulasikan terlebih dahulu menggunakan sebuah EM Simulator AWR Design Environment, sehingga mendapatkan hasil respon duplexer yang diharapkan. 


\section{METODOLOGI}

\subsection{Perancangan simulasi}

Perancangan sebuah duplexer dilakukan dengan cara menggabungkan dua buah Coupler dan dua buah Bandstop filter. Coupler yang akan dirancang menggunakan metode Hybrid Coupler $90^{\circ}$, yaitu Coupler yang memiliki kopling $-3 \mathrm{~dB}$ serta beda fasa $90^{\circ}$ pada keluarannya. Sedangkan untuk Bandstop filter berbasis Split Ring Resonator yang memiliki kelebihan yaitu ukuran filter dapat diperkecil sehingga ukuran keseluruhan alat menjadi lebih kecil. Duplexer ini bekerja pada band frekuensi ke-7 pada teknologi LTE dengan skema duplexing FDD, yang menggunakan frekuensi uplink $2500-2570 \mathrm{MHz}$ dan frekuensi downlink 2620-2690 MHz. Kemudian untuk melakukan perancangan duplexer, hal yang dilakukan pertama adalah menentukan frekuensi kerja atau perancangan sistem, kemudian menghitung terlebih dahulu panjang dan lebar untuk saluran mikrostrip. Penggunaan EM Simulator AWR Design Environment bertujuan untuk melihat hasil respon Coupler dan Bandstop filter. Kemudian mengatur panjang dan lebar saluran mikrostrip agar mendapatkan hasil respon yang diharapkan. Lalu mengimplementasikan dengan cara mencetak pada PCB serta menggabungkan saluran mikrostrip untuk Coupler dan Bandstop filter agar menjadi sebuah duplexer dengan proses penyolderan. Kemudian mengukur hasil implementasi tersebut dan mengukur untuk mengetahui hasil respon keluarannya. Kemudian membandingkan dengan simulasi. Flowchart perancangan dan implementasi untuk duplexer ditunjukkan pada Gambar 1 untuk memudahkan pembaca agar memahami alur perancangan dan implementasi penelitian ini, serta Gambar 2 menunjukkan blok diagram Duplexer.
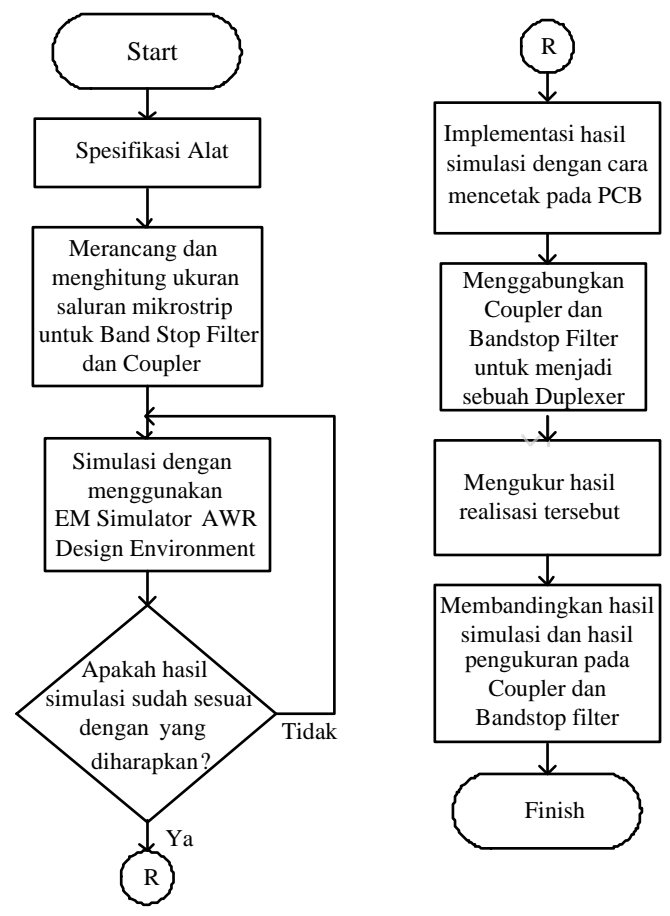

Gambar 1. Flowchart perancangan dan implementasi duplexer 


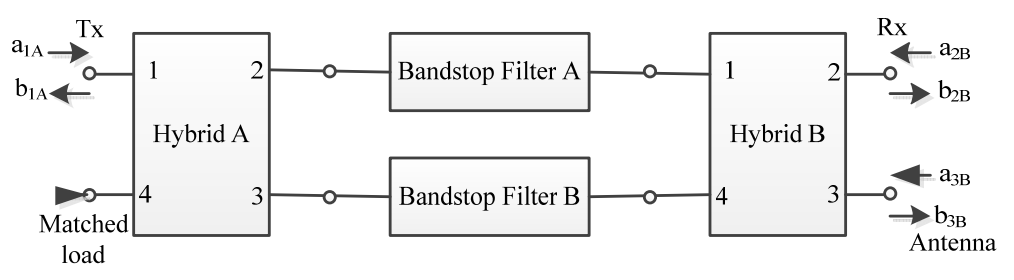

Gambar 2. Blok diagram Duplexer

\subsection{Perhitungan pada simulasi (Hong, 2001).}

Perhitungan yang dilakukan sebelum simulasi adalah menentukan lebar saluran mikrostrip $(W)$, konstanta dielektrik efektif, dan panjang saluran mikrostrip $(\lambda)$. Untuk keperluan perancangan, bila diketahui impedansi karakteristik Zo dan konstanta dielektrik $\varepsilon r$, lebar saluran (W) strip dapat dicari dengan Persamaan 1.

$$
\frac{W}{d}= \begin{cases}\frac{8 e^{A}}{e^{2 A}-2} & W / d<2 \\ \frac{2}{\pi}\left[B-1-\ln (2 B-1)+\frac{\varepsilon_{r}-1}{2 \varepsilon_{r}}\left(\ln (B-1)+0,39-\frac{0,61}{\varepsilon_{r}}\right)\right] & W / d>2\end{cases}
$$

Dengan A dan B menggunakan Persamaan 2,

$$
\begin{gathered}
A=\frac{Z_{0}}{60} \sqrt{\frac{\varepsilon_{r}+1}{2}}+\frac{\varepsilon_{r}-1}{\varepsilon_{r}+1}\left(0,23+\frac{0,11}{\varepsilon_{r}}\right) \\
B=\frac{377 \pi}{2 Z_{0} \sqrt{\varepsilon_{r}}}
\end{gathered}
$$

Kemudian menghitung konstanta dielektrik efektif menggunakan Persamaan 4,

$$
\varepsilon_{e}= \begin{cases}\frac{\varepsilon_{r}+1}{2}+\frac{\varepsilon_{r}-1}{2}\left(\left[1+\frac{12 d}{W}\right]^{-1 / 2}+0,04\left[1-\frac{W}{d}\right]^{2}\right) & W / d \leq 1 \\ \frac{\varepsilon_{r}+1}{2}+\frac{\varepsilon_{r}-1}{2}\left[1+\frac{12 d}{W}\right]^{-1 / 2} & W / d>1\end{cases}
$$

Lalu panjang saluran mikrostrip dapat menggunakan Persamaan 5,

$$
x_{g}=\frac{\epsilon}{f_{\sigma} \sqrt{g_{e}}}
$$

Dengan fc menggunakan Persamaan 6.

$$
f_{0}=\sqrt{f_{a} \cdot f_{b}}
$$




\section{HASI L PERANCANGAN DAN ANALISIS}

\subsection{Coupler}

Perancangan pada Coupler diharapkan memiliki kopling $-3 \mathrm{~dB}$ juga menghasilkan beda fasa $90^{\circ}$ pada keluarannya, ini merupakan metode yang digunakan yaitu Hybrid Coupler $90^{\circ}$. Gambar 3 menunjukkan Coupler beserta arah input dan outputnya. (Sulaeman, 2010)

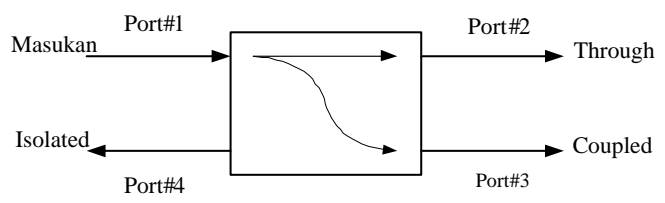

(a)

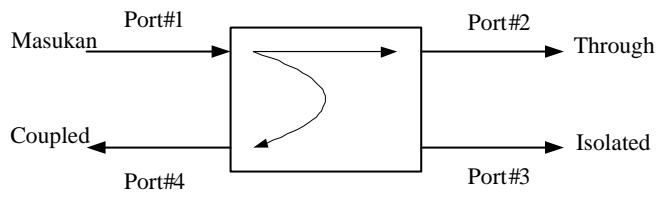

(b)

\section{Gambar 3. Four-port sebagai coupler (a) forward, (b) backward}

\subsubsection{Perancangan dan realisasi Coupler}

Setelah menghitung lebar dan panjang saluran mikrostrip untuk Coupler maka disimulasikan menggunakan EM Simulator AWR Design Environment untuk melihat hasil responnya. Hasil respon yang diharapkan adalah memiliki beda fasa $90^{\circ}$ pada frekuensi kerja Coupler yaitu, 2500-2690 MHz. Gambar 4 menunjukan hasil perancangan pada Coupler. Gambar 5 menunjukkan hasil respon frekuensi pada Coupler yang diharapkan memiliki kopling $-3 \mathrm{~dB}$ antara S21 (direct) dan S31 (kopling) serta hasil respon beda fasanya. Respon beda fasa yang diharapkan antara S21 (direct) dan S31 (kopling) adalah $90^{\circ}$.

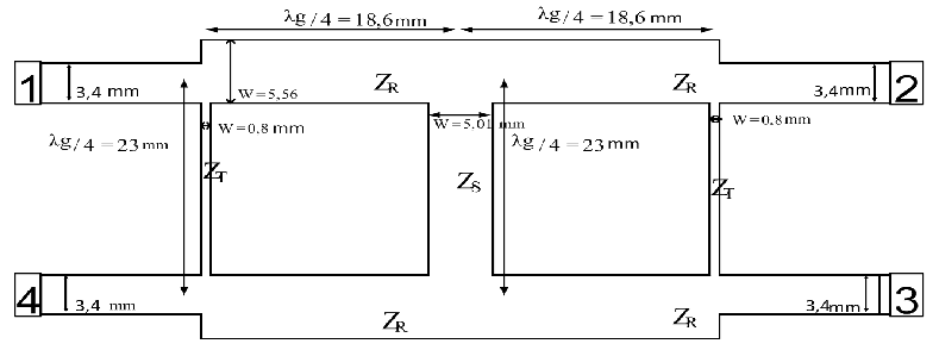

Gambar 4. Perancangan pada Coupler

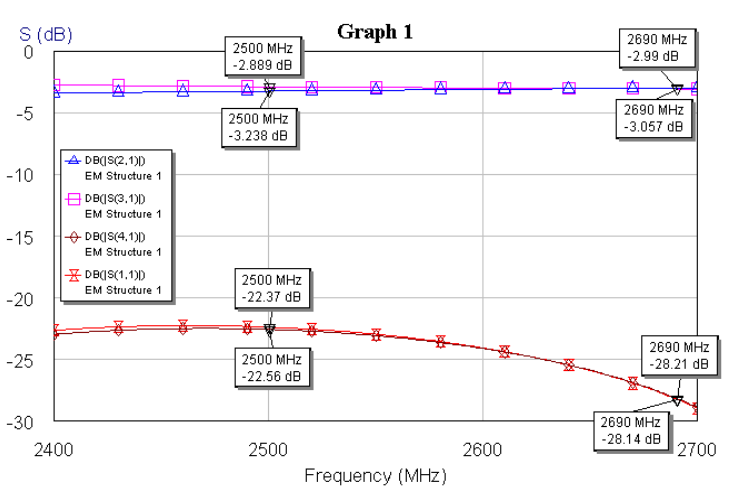

(a)

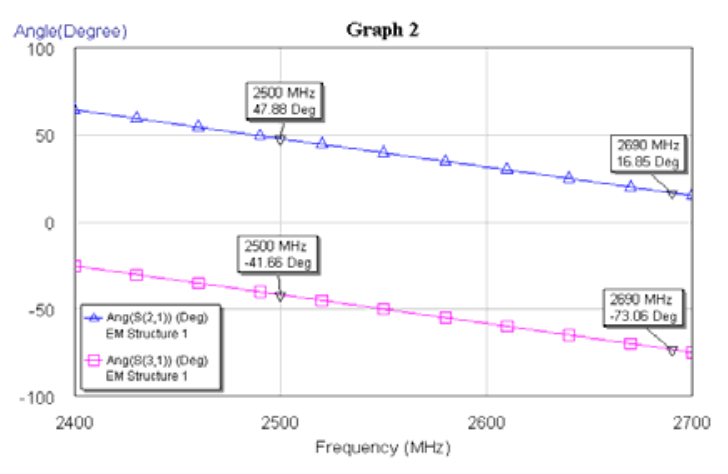

(b)

Gambar 5. Hasil (a) respon frekuensi, dan (b) respon fasa pada Coupler Jurnal Elkomika - 72 
Setelah mendapatkan hasil simulasi Coupler yang sudah sesuai dengan apa yang diharapkan, langkah selanjutnya adalah mengimplementasikan dengan cara mencetak pada PCB berjenis Taconic yang memiliki tebal $1.52 \mathrm{~mm}$ dan besar $\varepsilon_{m}=3.5$. Kemudian memasangkan konektor berjenis SMA gold pada ujung port-nya, seperti pada Gambar 6.

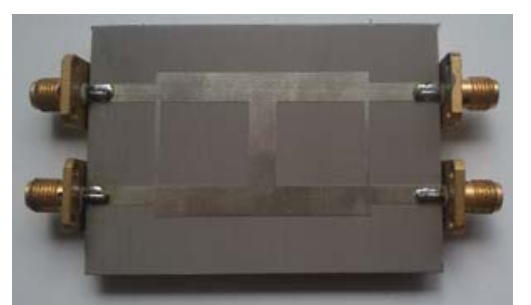

Gambar 6. I mplementasi Coupler

\subsubsection{Hasil pengukuran dan analisis Coupler}

Pengukuran dilakukan untuk mengetahui bagaimana hasil simulasi yang telah direalisasikan pada sebuah PCB berjenis Taconic dengan tebal $1.52 \mathrm{~mm}$ dan $\boldsymbol{\varepsilon}_{\mathrm{r}}-\mathbf{- 3 , 5}$, apakah sama dengan hasil simulasi sebelum direalisasikan. Gambar 7 merupakan gabungan dari hasil respon pengukuran dan simulasi menggunakan software MATLAB agar terlihat perbedaannya.

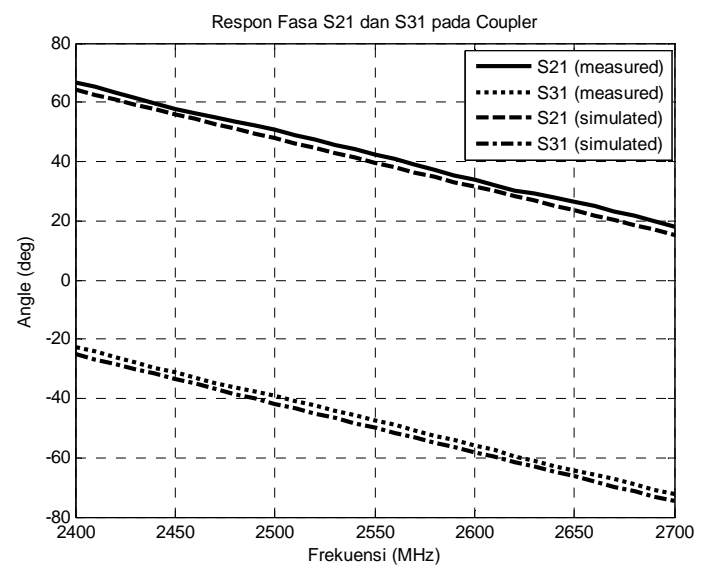

(a)

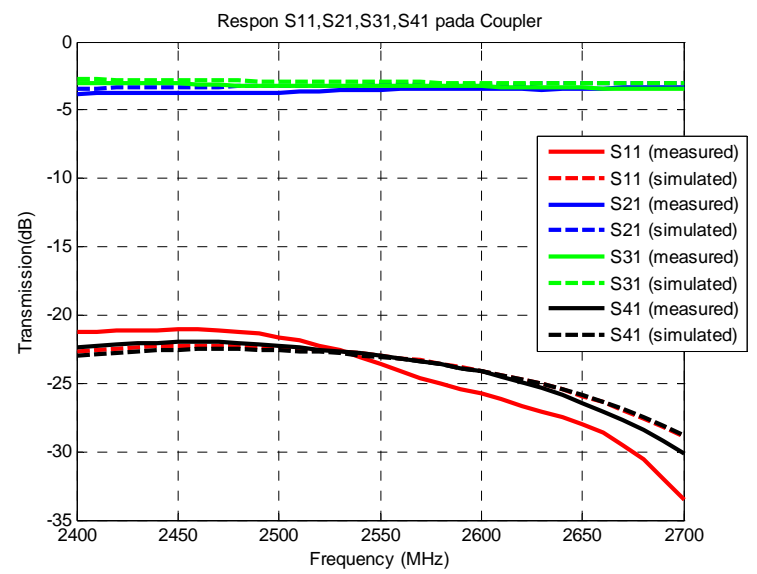

(b)

Gambar 7. Simulasi dan pengukuran (a) respon fasa, (b) respon frekuensi pada Coupler

Tabel 1 merupakan perbandingan hasil simulasi dan pengukuran untuk respon fasa yang diambil di dua titik sesuai dengan Gambar 7(a).

Tabel 1. Perbandingan hasil simulasi dan pengukuran pada Coupler

\begin{tabular}{|l|c|c|c|c|c|c|}
\hline & \multicolumn{3}{|c|}{$2500 \mathrm{MHz}$} & \multicolumn{3}{c|}{$2690 \mathrm{MHz}$} \\
\cline { 2 - 7 } & $\mathrm{S} 21$ & $\mathrm{~S} 31$ & $\Delta$ & $\mathrm{S} 21$ & $\mathrm{~S} 31$ & $\Delta$ \\
\hline Simulasi $\left({ }^{\circ}\right)$ & 47.88 & -41.66 & 89.54 & 16.85 & -73.06 & 89.91 \\
\hline Pengukuran ( $\left.{ }^{\circ}\right)$ & 50.57 & -39.15 & 89.72 & 19,73 & -70.67 & 90.4 \\
\hline
\end{tabular}

Sesuai dengan Tabel 1, terlihat bahwa terdapat perbedaan antara beda fasa saat simulasi dan pengukuran, hal ini dikarenakan pada saat simulasi menggunakan perfect conductor yang berarti saat simulasi dianggap tidak terdapat redaman, tetapi nyatanya setelah diimplementasikan redaman muncul dan tidak dapat diabaikan. Redaman yang muncul disebabkan pada proses penyolderan serta pada kabel-kabel saat pengukuran. 


\subsection{Band Stop Filter}

Band Stop Filter berfungsi untuk meredam frekuensi uplink (2500-2570 MHz) pada penelitian ini, dengan menggunakan metode Split Ring Resonator yang memiliki keuntungan ukuran filter dapat diperkecil, sehingga ukuran keseluruhan alat menjadi lebih kecil. Respon frekuensi yang diharapkan pada Bandstop filter ditunjukkan pada Gambar 8.

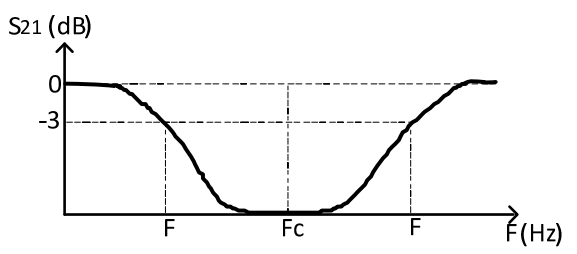

Gambar 8. Respon frekuensi Band Stop Filter(BSF)

\subsubsection{Perancangan Band Stop Filter}

Sama halnya dengan perancangan pada Coupler, yaitu sebelum melakukan simulasi dilakukan terlebih dahulu perhitungan untuk menentukan lebar dan panjang saluran untuk Bandstop filter. Bandstop filter bekerja pada frekuensi uplink yaitu $2500-2570 \mathrm{MHz}$ dengan frekuensi tengah $2535 \mathrm{MHz}$. Lalu mensimulasikan dengan EM Simulator AWR Design Environment agar mengetahui bagaimana respon dari Band Stop Filter mikrostrip tersebut. Gambar 9 menunjukkan perancangan dan hasil respon simulasinya.

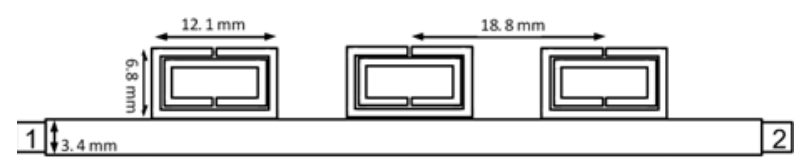

(a)

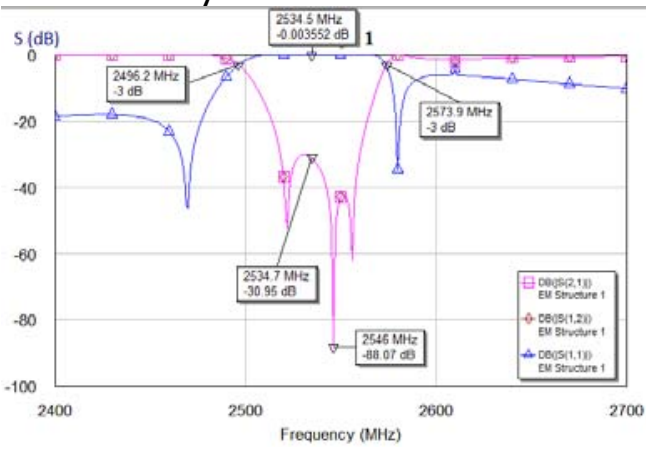

(b)

Gambar 9. (a) Perancangan, dan (b) Hasil respon Band Stop Filter

Gambar 9 menunjukkan hasil respon frekuensi. Pada bandwidth mendapatkan nilai sebesar $78 \mathrm{MHz}$, dengan redaman $>20 \mathrm{~dB}$, dan nilai Insertion Loss mendekati nol. Untuk mencapai spesifikasi yang tepat dengan perancangan awal, sangat sulit dilakukan. Proses simulasi ini membantu perancangan, sehingga dapat mendekati hasil yang diharapkan. Lalu dengan menambahkan elemen resonator menjadi tiga, bertujuan untuk mendapatkan hasil respon frekuensi yang mendekati filter ideal (filter yang lebih curam). Kemudian pada saat proses implementasi dilakukan, diharapkan tidak terlalu jauh dengan hasil yang telah disimulasikan ini. Langkah selanjutnya juga sama dengan implementasi pada Coupler yaitu dengan cara mencetak pada PCB berjenis Taconic yang memiliki tebal $1,52 \mathrm{~mm}$ dan besar $\varepsilon_{r}=3,5$. Kemudian memasangkan konektor berjenis SMA gold pada ujung port-nya, seperti pada Gambar 10.

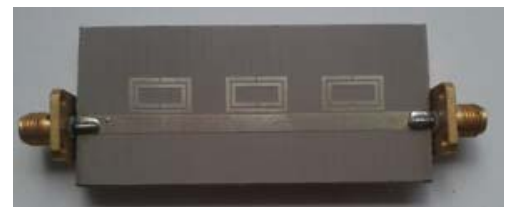

Gambar 10. I mplementasi Band Stop Filter

Jurnal Elkomika - 74 


\subsubsection{Hasil pengukuran dan analisis Band Stop Filter}

Hasil simulasi dan pengukuran untuk respon parameter S21 dan S11 pada Band Stop Filter dapat ditunjukkan pada Gambar 11 dengan menggabungkannya menggunakan software MATLAB. Terlihat bahwa terdapat pergeseran frekuensi tengah, hal ini mengakibatkan berubahnya nilai range frekuensi, frekuensi tengah, dan besarnya bandwidth pada saat perancangan, simulasi, dan pengukuran. Hasil perbandingan ketiga proses tersebut dapat dilihat pada Tabel 2.

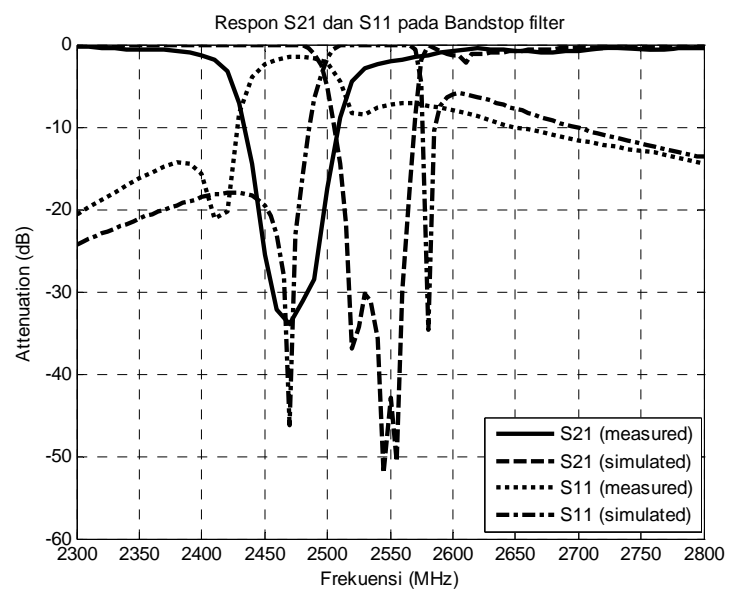

Gambar 11. Hasil simulasi dan pengukuran $S_{21}$ dan $S_{11}$ pada Band Stop Filter

Tabel 2. Perbandingan hasil perancangan, simulasi dan pengukuran pada Band Stop Filter

\begin{tabular}{|l|c|c|c|}
\hline \multicolumn{1}{|c|}{ Parameter } & Perancangan & Simulasi & Pengukuran \\
\hline Frekuensi tengah $\left(f_{o}\right)(\mathrm{MHz})$ & 2535 & 2534.7 & 2474.4 \\
\hline Range Frekuensi $(\mathrm{MHz})$ & $2500-2570$ & $2496.2-2573.9$ & $2420-2530$ \\
\hline Bandwidth $(\mathrm{MHz})$ & 70 & 77.7 & 110 \\
\hline
\end{tabular}

Pergeseran frekuensi tengah disebabkan oleh tidak presisinya jalur yang dibuat, sehingga pada saat pengukurannya membuat range frekuensi bergeser serta nilai bandwidth yang membesar, juga adanya redaman yang ditimbulkan pada proses penyolderan yang kurang baik serta pada kabel-kabel saat pengukuran. Juga pada saat simulasi perfect conductor yang berarti saat simulasi dianggap tidak terdapat redaman, tetapi nyatanya setelah diimplementasikan redaman muncul dan tidak dapat diabaikan. Redaman yang sangat besar ini mengakibatkan nilai bandwidth membesar sehingga nilai faktor kualitas menurun, seperti ditunjukkan pada Tabel 3 yang menggunakan persamaan faktor kualitas.

Tabel 3. Perbandingan nilai faktor kualitas

\begin{tabular}{|c|c|c|}
\hline \multicolumn{3}{|c|}{$Q=\frac{f_{C}}{B W}=\frac{f_{c}}{\ell_{2}-f_{1}}$} \\
\hline Perancangan & Simulasi & Pengukuran \\
\hline$Q=\frac{f_{Q}}{B W}=\frac{2535}{70}=36.21$ & $Q=\frac{f_{o}}{B W}=\frac{2534.7}{77.7}=32.62$ & $Q-\frac{f_{Q}}{B W}-\frac{24.74 .4}{110}-22.49$ \\
\hline
\end{tabular}

Berdasarkan pada Tabel 3, semakin besar nilai Q, maka semakin tinggi nilai selektivitasnya, dan sebaliknya jika semakin kecil nilai $Q$, maka semakin rendah nilai selektivitasnya, dan ini 
mempengaruhi filter saat melewatkan maupun meredam sinyal yang diinginkan. Kemudian pengaruh saat pemilihan jenis konektor, dan proses pemasangan konektor yang tidak baik pada proses implementasi sangat mempengaruhi hasil pengukurannya.

\subsection{Duplexer}

Setelah mengimplementasikan Coupler dan Bandstop filter langkah selanjutnya adalah dengan cara menggabungkan kedua sistem tersebut menjadi satu dengan cara proses penyolderan, sehingga Coupler dan Bandstop filter bersatu menjadi sebuah sistem yang dinamakan Duplexer. Dapat dilihat pada Gambar 12 yang merupakan hasil penggabungan Coupler dan Bandstop filter dengan proses penyolderan sehingga menjadi sebuah Duplexer dengan memasangkan empat buah konektor berjenis SMA gold pada sisi ujung port-nya.

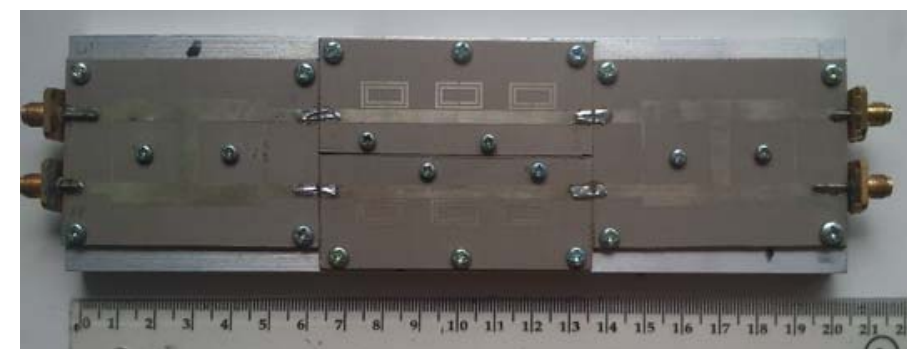

Gambar 12. I mplementasi Duplexer

Pada Gambar 13 merupakan hasil pengukuran pada duplexer. Dilihat dari hasil pengukuran tersebut, terjadi pergeseran pada frekuensi uplink, hal ini disebabkan karena respon Bandstop filter yang dihasilkan pun bergeser frekuensinya. Kemudian faktor beda fasa yang dihasilkan pada Coupler pun mempengaruhi, karena respon Coupler yang dihasilkan kurang dan lebih dari $90^{\circ}$, yaitu $89.72^{\circ}$ dan $90.4^{\circ}$, karena untuk mendapatkan $90^{\circ}$ yang tepat sangat sulit untuk direalisasikan. Namun saat hasil respon pengukuran fasa parameter S21 dan S31 pada Coupler menggunakan software MATLAB ternyata mendekati $90^{\circ}$ untuk setiap frekuensinya, seperti pada Gambar 14. Namun apabila dengan ketelitian yang sangat besar pada saat menggunakan software MATLAB akan terlihat tenyata pada setiap frekuensinya tidak $90^{\circ}$, bahkan besarnya sudut naik turun walaupun hanya dua angka dibelakang koma. Dapat dilihat pada Gambar 15, dengan tidak tepatnya fasa yang dihasilkan oleh Coupler menyebabkan hasil kinerja pengukuran pada duplexer tidak seoptimal mungkin pada saat mengirim atau bahkan menerima sinyal saat waktu bersamaan dan tanpa adanya kebocoran.

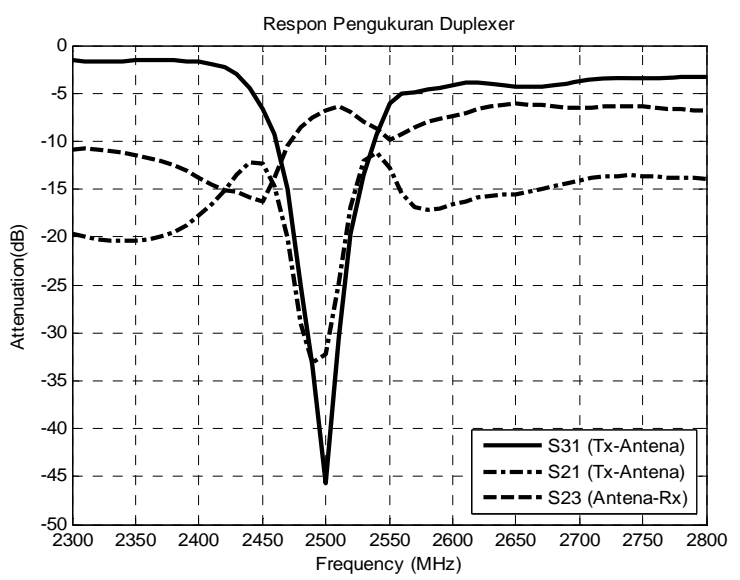

Gambar 13. Hasil pengukuran Duplexer

Jurnal Elkomika - 76 
Pada respon parameter S31, merupakan port Tx menuju ke Antenna menghasilkan respon yang cukup baik, karena pada saat Tx menuju Antena bekerja pada saat frekuensi downlink, sehingga untuk frekuensi uplink diredam sebesar mungkin, sedangkan untuk frekuensi downlink dipancarkan sebesar-besarnya. Hasil pengukuran parameter S31 untuk frekuensi tengah uplink dihasilkan sebesar $45.612 \mathrm{~dB}$ sedangkan untuk frekuensi tengah downlink dihasilkan redaman sebesar $3.168 \mathrm{~dB}$. Pada frekuensi uplink dengan nilai tersebut sudah cukup baik karena $>20 \mathrm{~dB}$, sedangkan untuk frekuensi downlink (frekuensi yang digunakan pada saat Tx memancarkan sinyal menuju ke antena) dengan nilai redaman $3.168 \mathrm{~dB}$ tersebut kurang baik karena akan mempengaruhi sinyal yang akan dipancarkan. Hal ini juga dipengaruhi dari respon fasa pada Coupleryang beda fasanya tidak $90^{\circ}$.

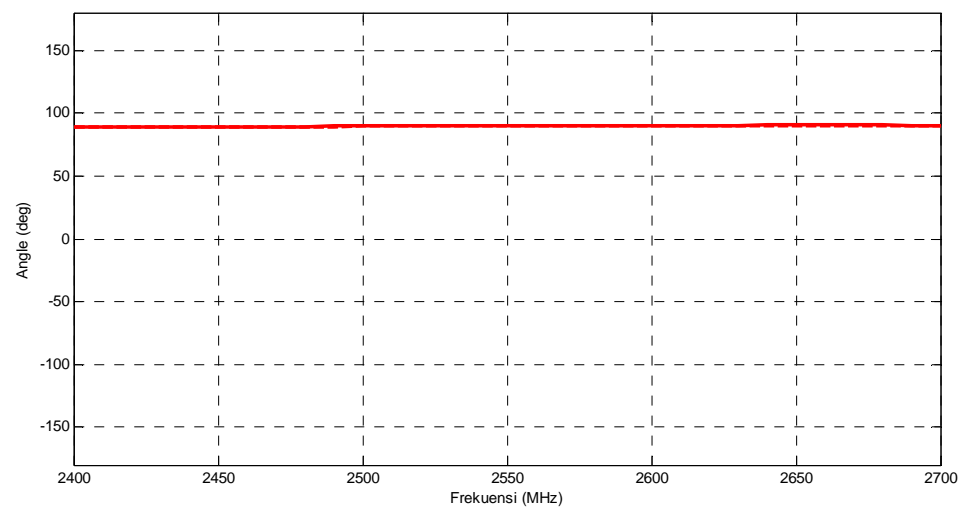

Gambar 14. Respon fasa $s_{21}$ dan $s_{31}$ pada Coupler dengan 90은

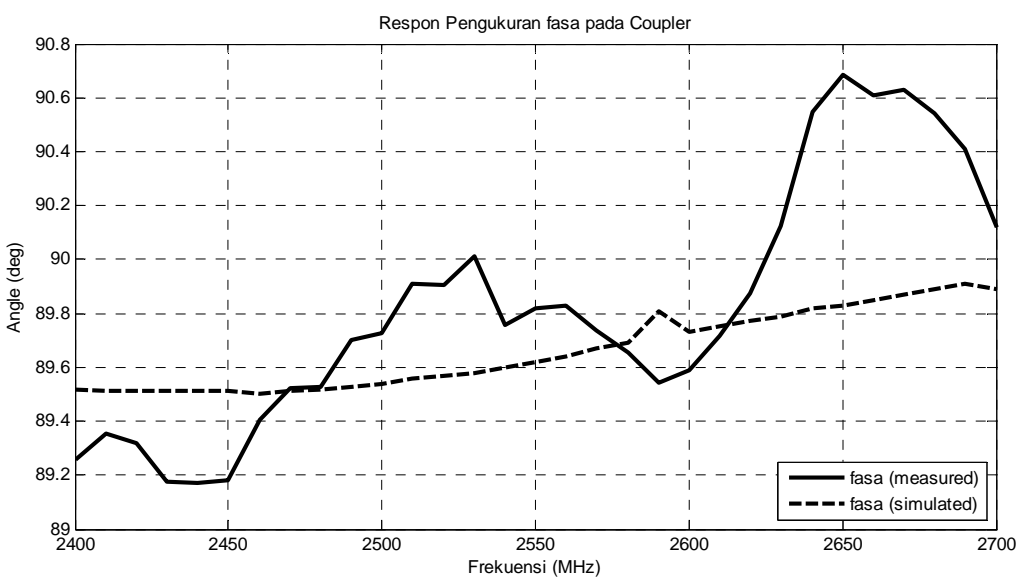

Gambar 15. Respon fasa $s_{21}$ dan $s_{31}$ pada Coupler dengan \pm 900

Kemudian hasil pengukuran respon parameter S21 yang merupakan isolasi, diharapkan meredam sinyal sebesar-besarnya, ini dikarenakan pada saat Tx akan memancarkan sinyal melalui antena, tidak ada sinyal yang masuk ke Rx. Ini merupakan salah satu fungsi dari duplexer, yaitu mengatur sinyal agar tidak terjadi kebocoran saat menerima dan mengirim sinyal, karena keduanya terjadi pada waktu yang bersamaan. Pada Gambar 13, hasil respon parameter S21 sudah cukup baik yaitu dihasilkan redaman sebesar $32 \mathrm{~dB}$ pada frekuensi tengah uplink sedangkan pada frekuensi tengah downlink dihasilkan redaman sebesar $15 \mathrm{~dB}$. Tabel 4 menunjukkan hasil nilai redaman yang dihasilkan pada saat pengukuran duplexer. 
Tabel 4. Nilai Redaman pada Duplexer

\begin{tabular}{|l|c|c|}
\hline \multirow{2}{*}{ Parameter } & \multicolumn{2}{|c|}{ Attenuation (dB) } \\
\cline { 2 - 3 } & $\begin{array}{c}\text { Frekuensi Uplink } \\
(2420-2530 \mathrm{MHz})\end{array}$ & $\begin{array}{c}\text { Frekuensi Downlink } \\
(2620-2690 \mathrm{MHz})\end{array}$ \\
\hline $\mathrm{S}_{31}(\mathrm{Tx}-$ Antena) & 45.612 & 3.168 \\
\hline $\mathrm{S}_{21}(\mathrm{Tx}-\mathrm{Rx})$ & 32 & 15 \\
\hline $\mathrm{S}_{23}$ (Antena - Rx) & 6 & 6.5 \\
\hline
\end{tabular}

Lalu untuk hasil pengukuran respon parameter S23, dimana antena akan menerima sinyal dari user yang akan diteruskan ke Rx, hasilnya kurang baik karena pada frekuensi uplink di sisi passband didapatkan nilai redaman sebesar $6 \mathrm{~dB}$. Nilai ini akan mempengaruhi sinyal yang diterima oleh Rx. Hal ini dikarenakan adanya redaman yang sangat besar yang ditimbulkan kurang tepatnya fasa pada Coupler seperti yang telah ditunjukkan pada Gambar 15.

\section{KESI MPULAN}

Berdasarkan perancangan, proses simulasi dan hasil pengukuran maka diperoleh kesimpulan sebagai berikut :

1. Pengukuran pada Coupler dihasilkan respon fasa yang linier dengan beda fasa di frekuensi $2500 \mathrm{MHz}$ adalah sebesar $89.72^{\circ}$, serta di frekuensi $2690 \mathrm{MHz}$ dihasilkan 90.40. Dihasilkan beda fasa saat pengukuran dengan simulasi di frekuensi $2500 \mathrm{MHz}$ dan $2690 \mathrm{MHz}$ sebesar $0.18^{\circ}$ dan $0.49^{\circ}$.

2. Band Stop Filter menghasilkan respon frekuensi yang bergeser dari hasil respon simulasinya yaitu frekuensi tengah menjadi $2474.4 \mathrm{MHz}$ serta range frekuensi 2420 $2530 \mathrm{MHz}$ dan bandwidth sebesar $110 \mathrm{MHz}$ sedangkan pada simulasinya besarnya bandwidth $77 \mathrm{MHz}$. Redaman yang terjadi pada frekuensi downlink sebesar $0.7 \mathrm{~dB}$.

3. Pada duplexer, Tx mengirimkan sinyal ke antena dengan nilai redaman pada frekuensi tengah downlink sebesar $3.168 \mathrm{~dB}$. Lalu pada saat antena menerima sinyal untuk diteruskan ke Rx terdapat redaman di frekuensi tengah uplink sebesar $6 \mathrm{~dB}$. Kemudian untuk isolasi dari port Tx-port Rx dihasilkan $15 \mathrm{~dB}$.

\section{DAFTAR RUJ UKAN}

Siburian, S. (2011). Pengenalan Teknologi Long Term Evolution. Sumatra Utara : Universitas Sumatera Utara.

Wijayanti, Indah. (2010). Realisasi dan Analisis BSF Duplexer Microstrip Pada Frekuensi Uplink 2500-2570MHz dan Downlink 2620-2690MHz. Bandung : Institut Teknologi Telkom.

Hong, Jia-Sheng. dan Lancaster, M.J. (2001). Microstrip Filter for RF/Microwave Applications. Case Study For Mobile Communications Applications. Canada.

Hong, Jia-Sheng. dan Lancaster, M.J. (2001). Microstrip Filter for RF/Microwave Applications. Transmissions Lines and Components. Canada.

Sulaeman, Enceng Ir. (2010). Bahan Ajar Kuliah : Power Divider \& Directional Coupler, Program Studi Teknik Telekomunikasi. Bandung : Politeknik Negeri Bandung. 